\title{
CHEMOTHERAPY OF LEPROSY CHIEFLY WITH SULFAMETHOXYPYRIDAZINE
}

\author{
by Tadashi Hirako, m.D.* and Hosaku Sakurai, m.D. $†$
}

In Japan, the use of chemotherapy with sulphonamide such as Promine DDS, etc., for leprosy has been widely practised since about 1950. This type of treatment has been so successful, that along with the merit of early-diagnosis and treatment, there is a good possibility of the leprosy patients being allowed to return to their communities after treatment. However in 1955, we found some relapsing cases, and the majority of them were resistant to Promine. In our leprosarium (Tama Zenshoen), about 1200 patients were admitted and there were approximately 30 relapsing cases each year (Table 1). Because of this we changed to use of DDS for these Promine-resistant cases. These cases improved temporarily, but soon became resistant to DDS. Next, we treated them by thiourea derivatives, but they became non-effective after two years treatment, and drug resistance once again appeared. One of the interesting things noted on the chemotherapy of leprosy is the following: Promine as you know, is one of the DDS derivatives, nevertheless, DDS is effective in Promine-resistant relapsing cases. This has been observed not only in sulphonamides but also in thiourea derivatives. Similarly, cases which are resistant to Dimethylamino T.C. (TAMEMASA) were susceptible to Butoxy T.C. (BUU HOI). These features of lepra bacilli are not seen in other bacteria. This situation encourages the trial of Sulfamethoxypyridazine for relapsing cases as well as new cases of leprosy.

\section{Table 1. Relapsing Cases by Years.}

\begin{tabular}{|c|c|c|c|c|c|c|c|c|}
\hline Type & $\begin{array}{l}\text { Year } \\
\text { '54 }\end{array}$ & 55 & '56 & '57 & '58 & '59 & '60 & '61 \\
\hline Lepromatous & 13 & 63 & 26 & 21 & 39 & 41 & 48 & 40 \\
\hline Non-Lepromatous & 2 & 3 & 2 & 2 & 3 & 0 & 3 & 1 \\
\hline
\end{tabular}

Sulfamethoxypyridazine also has been useful for tuberculosis, so we felt that it will be beneficial for leprosy. This is another reason for using Sulfamethoxypyridazine as a treatment for leprosy.

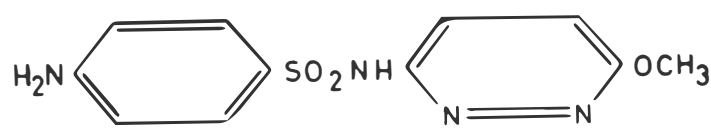

Sulfamethoxypyridazine "Lederkyn"

* National Leprosarium Tamazenshoen.

† National Leprosarium Nagashima aiseien. 


\section{Materials and methods}

(1) $0.75 \mathrm{gm}$ every other day, given orally to 55 cases.

(2) 0.5 gm daily, given orally to 45 cases.

The number of treated cases with Sulfamethoxypyridazine was 100, and all were lepromatous leprosy. (Table 2).

\section{Table 2. Number of Cases}

1. New case

2. Relapsing case

(i) simple relapsing case

(ii) drug-resistant relapsing case

3. Cases that had failed to become bacteriologically negative by other drugs and changed

4. Others ver to 'Lederkin'

Periods of medications

24 Months
18 "
12
6
3 " "
less than 3 Months

\section{Evaluation of treatment results}

\section{Effective}

Ineffective

(Epithelioid cell react.)

\begin{tabular}{|c|c|c|}
\hline $\begin{array}{c}\text { Method I } \\
13\end{array}$ & $\begin{array}{r}I I \\
2\end{array}$ & $\begin{array}{c}\text { Total } \\
15\end{array}$ \\
\hline $\begin{array}{r}0 \\
24\end{array}$ & $\begin{array}{r}3 \\
49\end{array}$ & $\begin{array}{r}3 \\
73\end{array}$ \\
\hline $\begin{array}{l}4 \\
4\end{array}$ & 0 & 4 \\
\hline 45 & 55 & 100 \\
\hline $\begin{array}{c}\text { Method I } \\
0 \\
3 \\
10 \\
21 \\
5 \\
6\end{array}$ & $\begin{array}{r}I I \\
9 \\
7 \\
8 \\
8 \\
15 \\
8\end{array}$ & $\begin{array}{c}\text { Total } \\
9 \\
10 \\
18 \\
29 \\
20 \\
14\end{array}$ \\
\hline 45 & 55 & 100 \\
\hline $\begin{array}{c}\text { Method I } \\
42 \\
3 \\
(4)\end{array}$ & $\begin{array}{c}I I \\
54 \\
1 \\
(5)\end{array}$ & $\begin{array}{c}\text { Total } \\
96 \\
4 \\
(9)\end{array}$ \\
\hline 45 & 55 & 100 \\
\hline
\end{tabular}

\section{Discussion}

This drug was effective to both new and old cases. Erythema nodosum leprosum has been observed in several cases.

For the past two years or so, on patients in which Sulfamethoxypyridazine has been used for antileprotic purpose, no particular side effects including deleterious actions on the liver, kidney, or hematopoietic system have been observed. Some of the patients have complained of gastric disturbance due to the oral administrations, but this complaint has not been such as would call for discontinuation of treatment.

Drug resistance appeared from about one and a half year to two years and only a small number of cases have shown relapsing (Fig. 1).

During the treatment with Sulfamethoxypyridazine, Epithelioid cell reaction or so called Pseudoexacerbation de Souza Lima was observed sometimes. When this reaction occurred in lepromatous 
cases, all clinical findings became similar with those of tuberculoid cases. Lepromin reaction became positive, serologic lepra reaction became positive to negative and also, bacilli soon became negative.

After close examination of the early discharged lepromatous cases, it was found that almost all these patients revealed that Epithelioid cell reaction was regarded to be Pseudoexacerbation.

Therefore, we think that it is necessary for the treatment of chronic inflammatory diseases such as tuberculosis, leprosy, etc., to use not only drugs, but also to use this biological action. Utilization of biological action as a means of cure, helps speed up the course of treatment of such chronic inflammatory diseases.

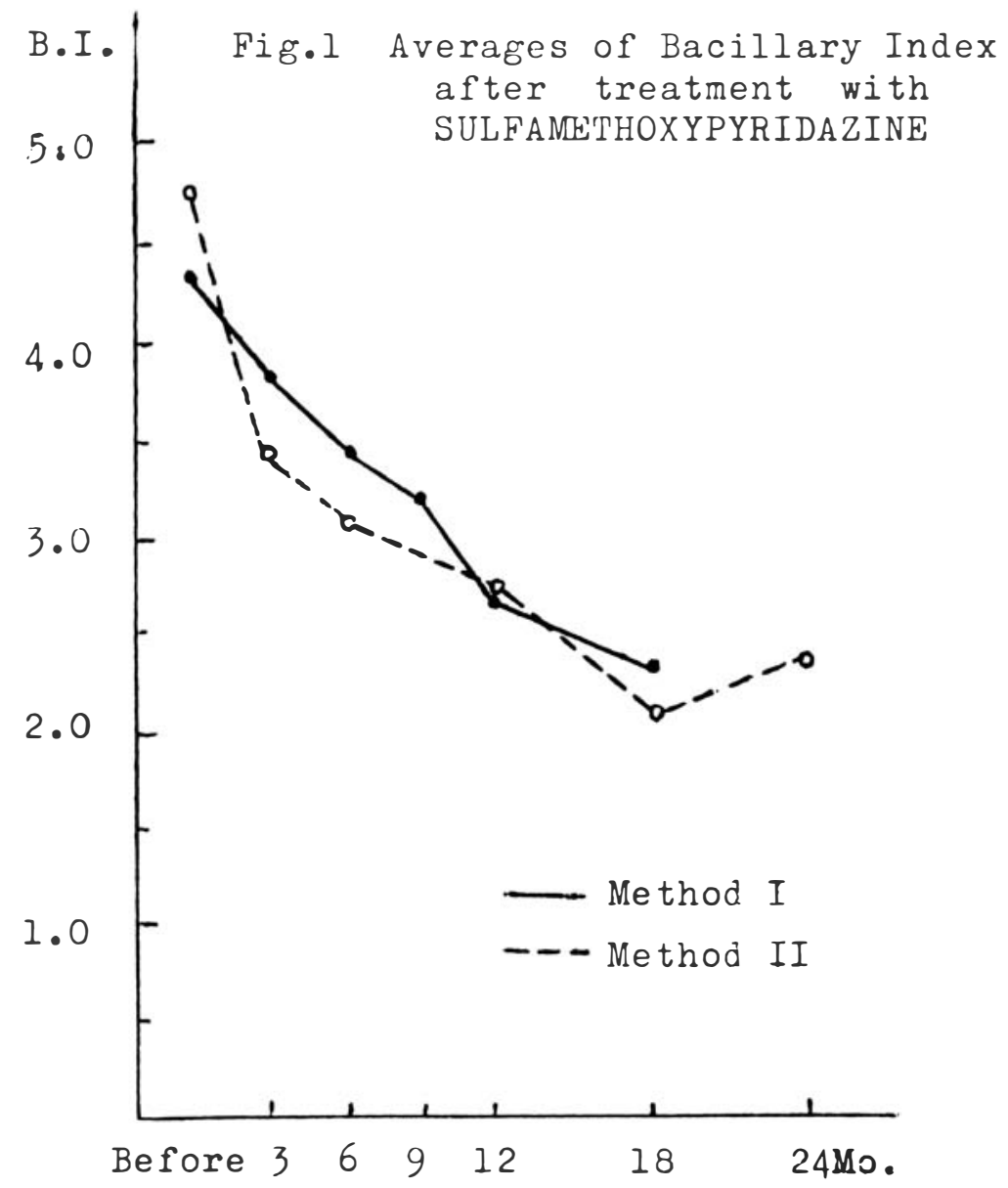

Epithelioid cell reaction in lepromatous leprosy derives from two causes. One is Acute Infiltration Tajiri, due to relapse of the diseases. These patients, after years of treatment, develop a raised individual resistance to leprosy bacilli and the strong resistance thus acquired, 
Case 1. New lepromatous case. 32 years old
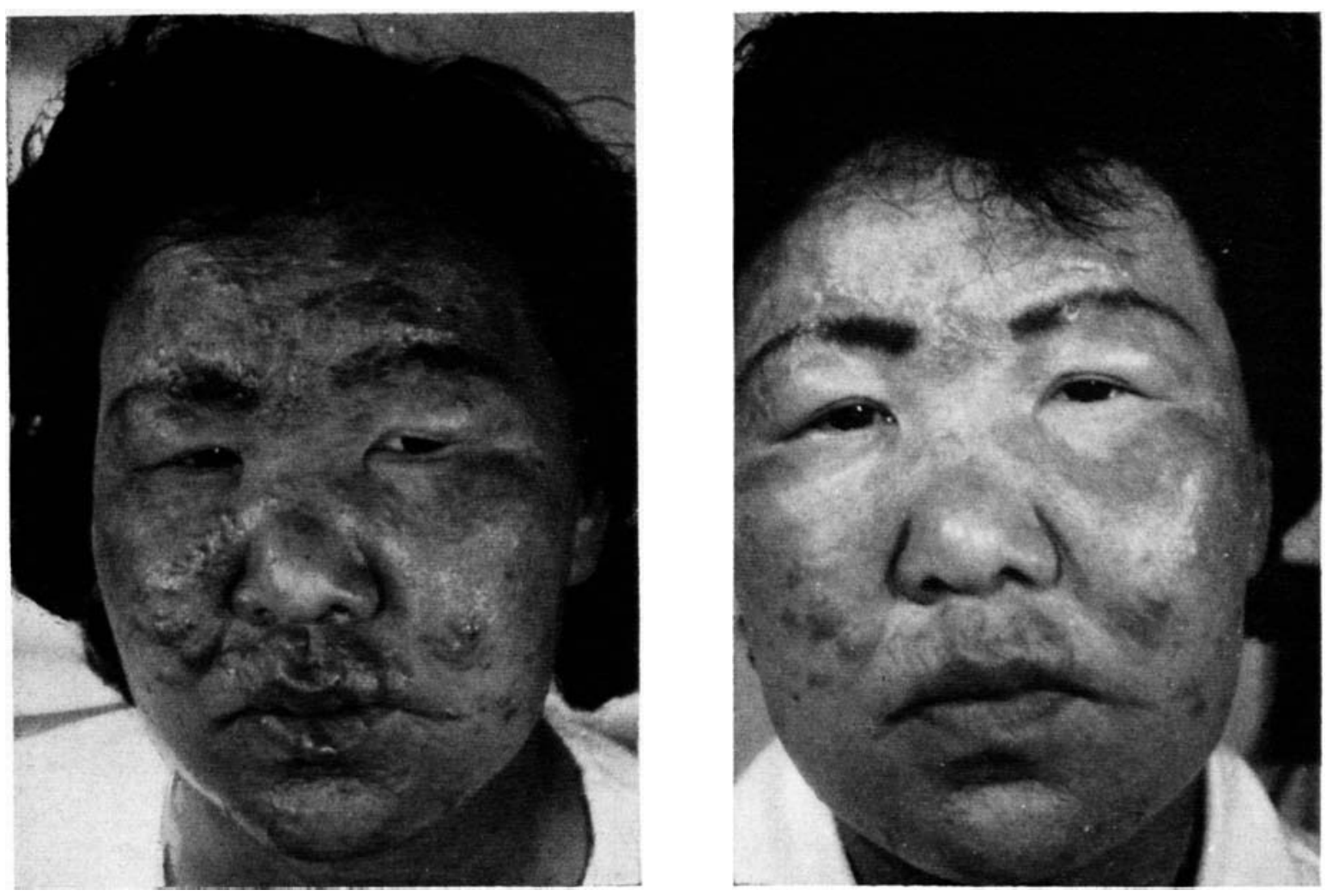

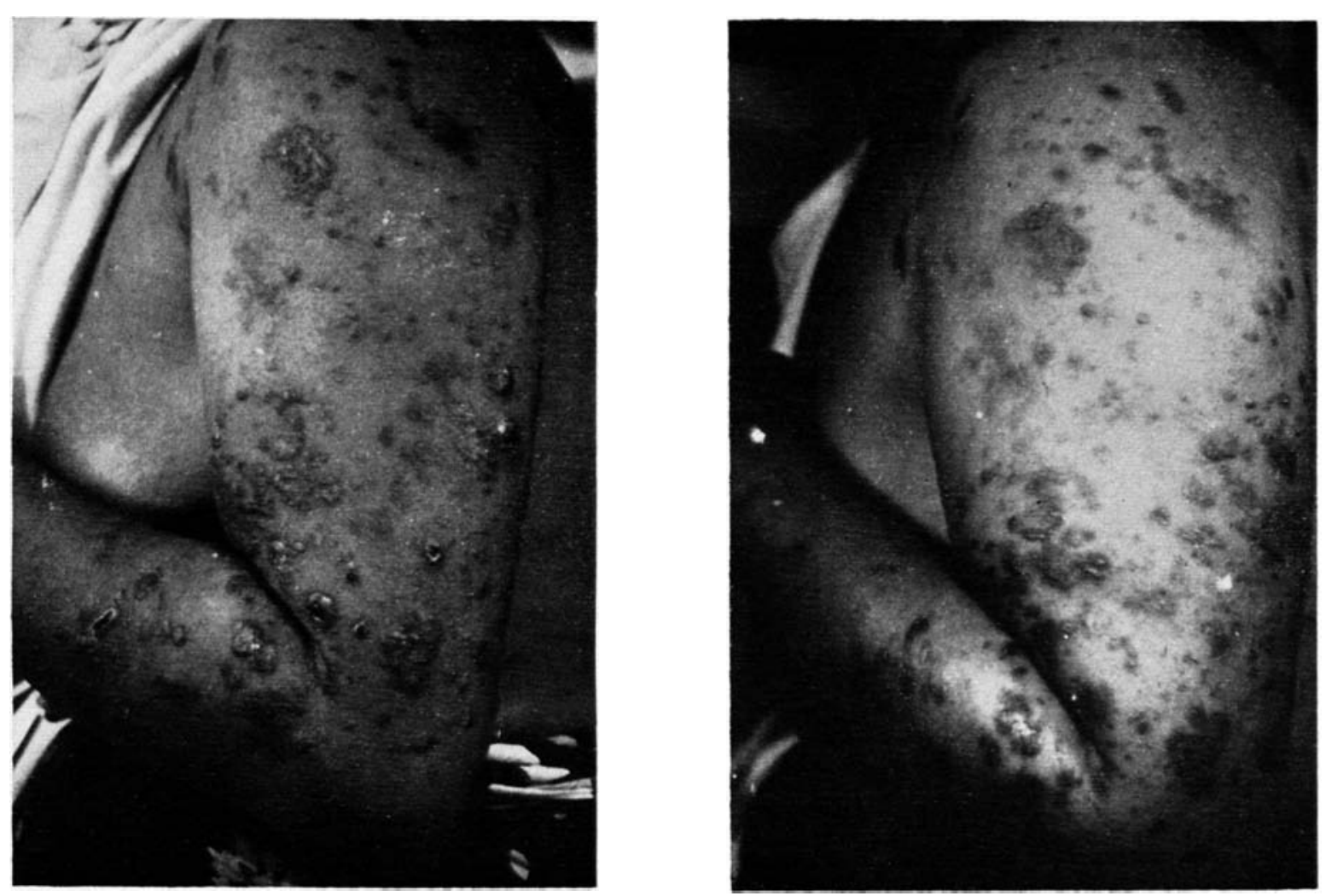

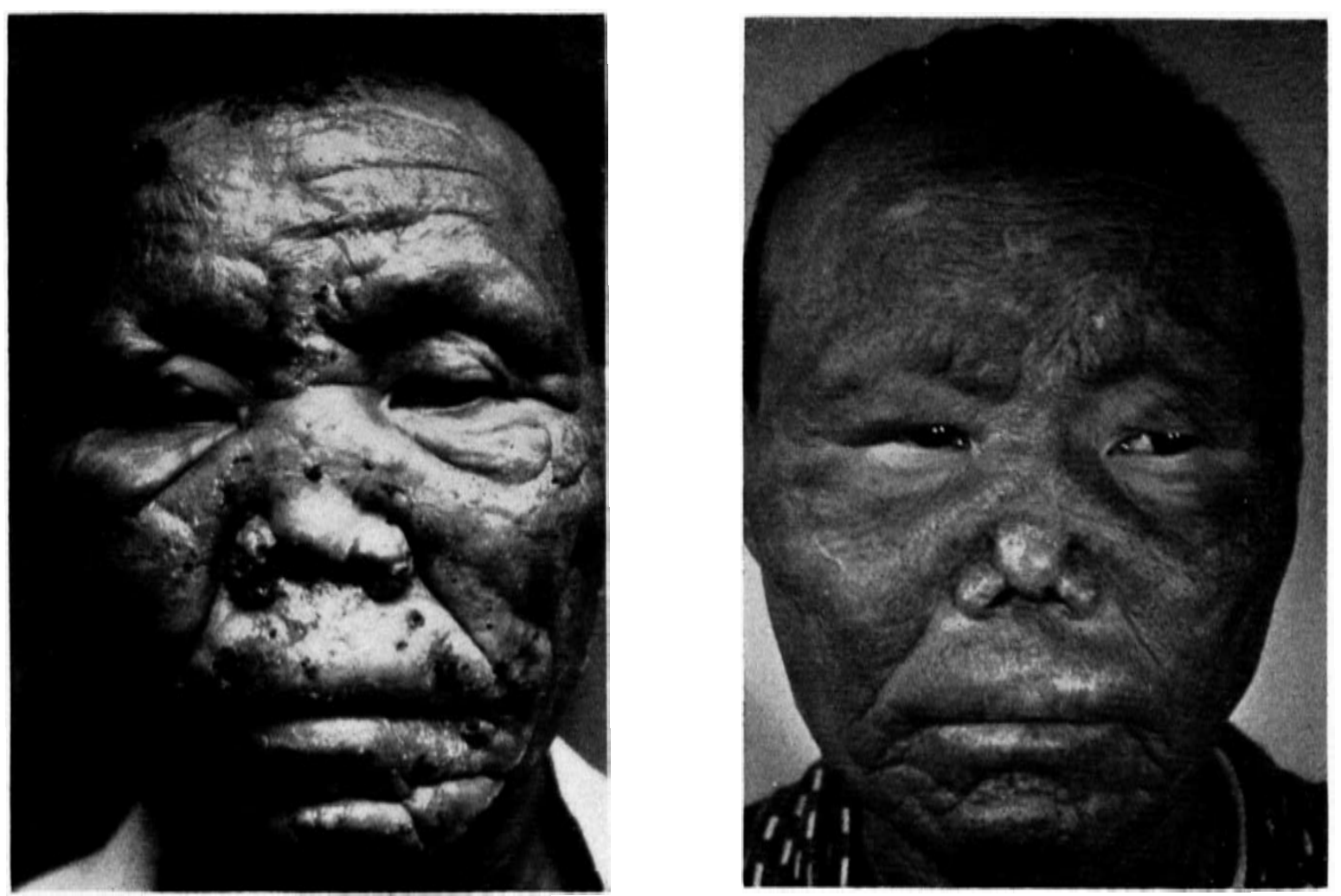
Case 3. Relapsing and DDS \& CIBA 1906-resistant lepromatous case. 34 years old,

Before the treatment

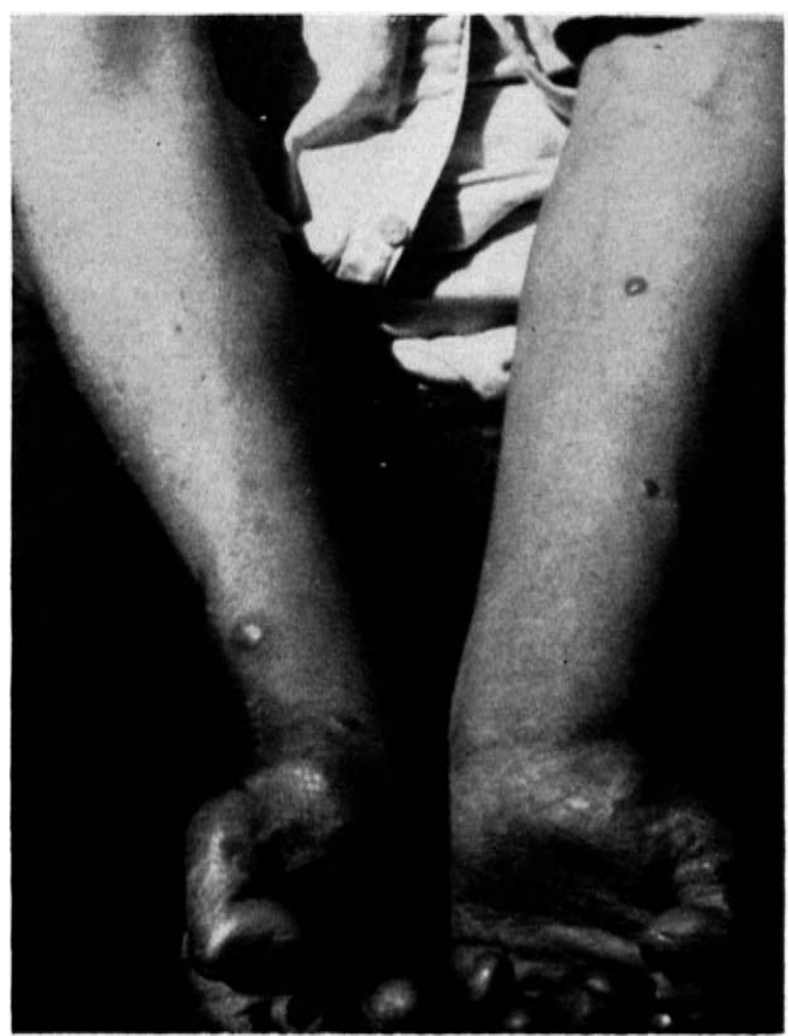

4 Mo. after the treatment

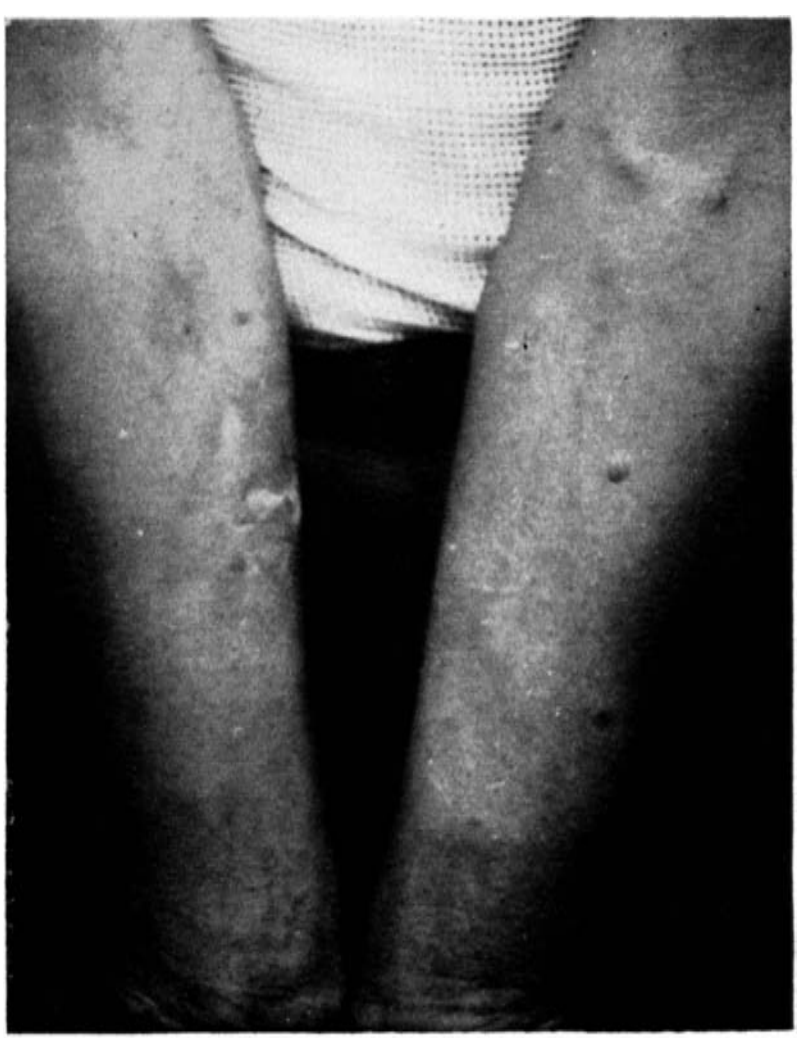


Case 4. Relapsing and DDS and CIBA 1906-Resistant lepromatous case.
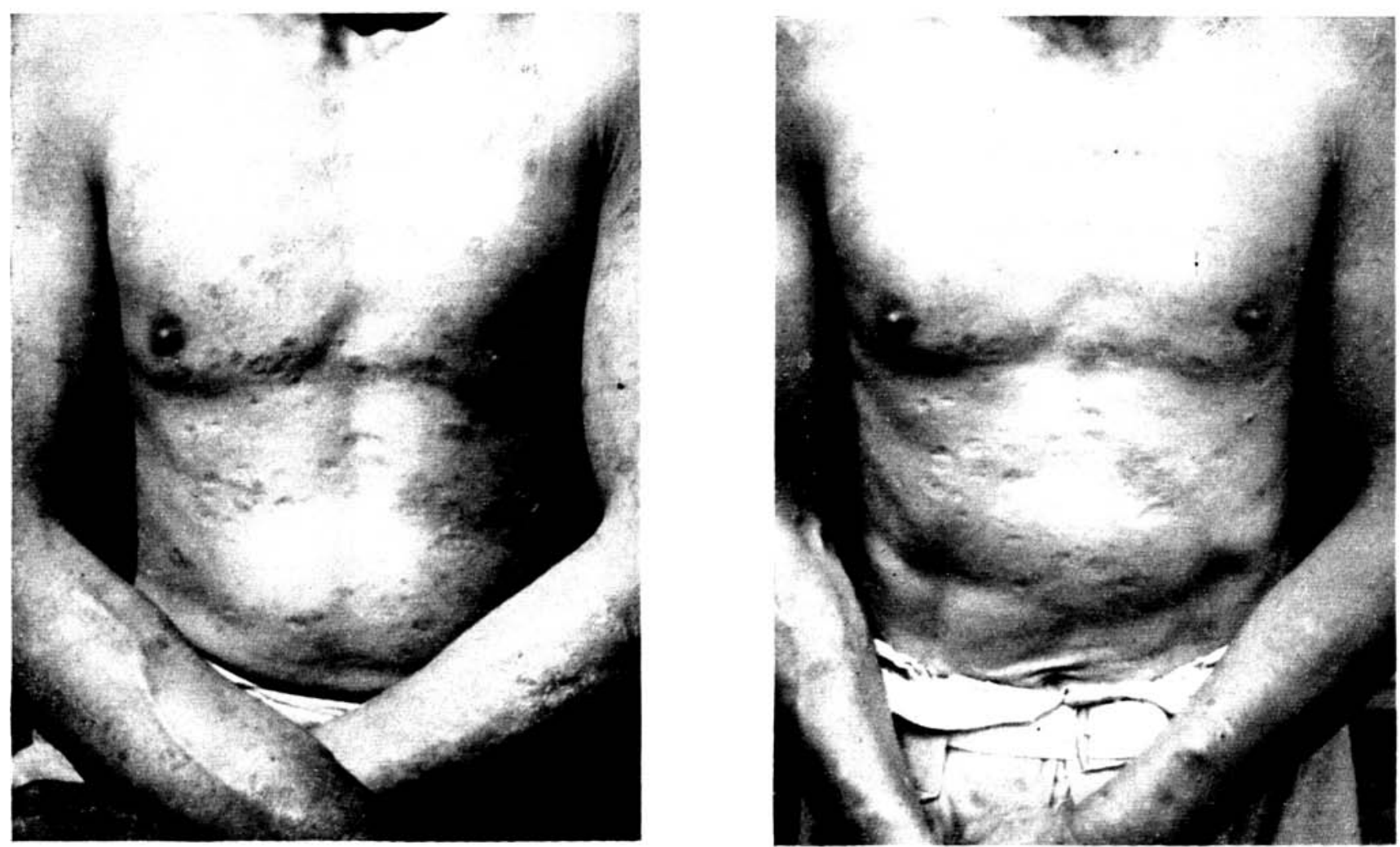
expressed itself as relapse with tuberculoid response. Since the use of chaulmoogra oil many years ago in Japan, several patients with the epithelioid cell reaction occurred and such causes have occurred every year. Since the common use of chemotherapy, the occurrence of such cases, as mentioned above, has increased, only a little, but still amounts to only a small proportion of the total number of cases.

This type of reaction, we shall call 'Secondary lepromatous improvement' since the pathologic improvement occurs as secondary to relapse of the disease.

Another substantial form of improved reaction 'Pseudoexacerbation de Souza Lima' has been observed only after the common use of chemotherapy. This type of reaction is seen within one year after the treatment. Cases with this type of reaction (improvement) have gradually increased due to early diagnosis and intensive treatment.

The latter type of improvement is designated as 'Primary lepromatous improvement', since this forms the substantial improvement of the pathological condition. And both types together, we shall call 'Epithelioid cell reaction in lepromatous leprosy'. Incidentally, these natures are the same as tuberculoid leprosy. The occurrence of the epithelioid cell reaction in the form of Pseudoexacerbation of lepromatous leprosy dates back to the initial clinical applications of sulphone drugs.

It is experimentally believed that sulphone drugs cause a strong activation of reticuloendothelial stimulation. Therefore, we believe this is the reason for the occurrence of this phenomenon. On the other hand, it is common knowledge that thiourea preparations produce a few reactive inflammations. In more than 100 cases given thiourea preparations in our leprosarium, the development of epithelioid cell reaction has not been observed in any of the cases, but in those cases using sulphone drugs this reaction occurs very often. It is believed that sulphone drugs cause a strong activation of the reticuloendothelial system, and Sulfamethoxypyridazine is able to remain long time in effective blood levels, consequently developing stronger and longer action on the R.E.S. than sulphonamide such as DDS or Promine, etc. In fact, the occurrence of epithelioid cell reaction was observed in 9 cases out of 100 cases given these drugs (about $10 \%$ ). Hence, sulfamethoxypyridazine may be regarded as very useful for the complete cure of leprosy and for shortening the period of treatment.

\section{Summary}

Sulfamethoxypyridazine has been used for drug-resistant, relapsing cases and for new cases making a total of about 100 lepromatous cases. This drug was effective in both new and old cases and had no particular side effect within the 24 months when 
observations have been done. During the treatment with sulphone drugs, Epithelioid cell reaction or so called Pseudoexacerbation de Souza Lima was observed. When this reaction occurs in lepromatous cases, all clinical findings became similar to those of tuberculoid cases and the bacilli also became negative soon.

So we consider that it is necessary for the treatment of chronic inflammatory diseases such as tuberculosis or leprosy, etc., not only to receive a specific drug but also to utilize this biological action.

\section{References}

Boger, W. P. et al.: Antibiot. Med., 3: 378, 1956.

Frisk, A. R. et al.: Antibiot. Ann. 1959, 1960, p. 868.

Frisk, A. R. et al.: Antibiot. Ann. 1956, 1957, p. 424.

Nichols, R. L. et al.: Proc. Soc. exp. Biol. (N.Y.), 92 : 637, 1956.

Nichols, R. L. et al.: J. Lah. clin. Med., 49: 410, 1957.

SChneider, J. et al.: Bull. Soc. Path. exot., 53: 173, 1960. 